\title{
Validating Auditors' Assumptions: A Measure of the Quality of Performance
}

\author{
Beverley A. Hollingsworth, Fitchburg State College, USA
}

\begin{abstract}
This study extends prior study to include formal training as an additional component of experience. Three research hypotheses tested the quality of auditor performance. Results showed formal training as significant. The sample consisted of 96 auditors with approximately two to nineteen years of audit and accounting experience. Previous work on auditors' experience and judgment produced mixed results. Those results do not consistently show that experience leads to better judgments. However, such work does not investigate the second component of experience included in this study. The study did not find on-the-job training to be effectively related to auditors' performance.
\end{abstract}

\section{INTRODUCTION}

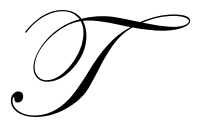

he third standard of fieldwork requires that auditors obtain sufficient competent evidential matter as a basis for formulating an opinion on an enterprise's financial statements. In defining evidential matter, the American Institute of Public Accountants' (AICPA) Statement on Auditing Standards No. 31 held that "evidential matter consists of both . . . the underlying accounting data and all corroborating information" (American Institute of Certified Public Accountants [AICPA], 1999c, p. 200).

Although the above statement underlines the importance of evidential matter, the accounting profession is still faced with the risk of audit failures. Auditors may be still be deficient in the evaluation strategies required to effectively validate their assumptions. It also appears that there is a difference in the ways in which more- and lessexperienced auditors collect and evaluate evidence. Furthermore, this difference may be a function of training and development or professional experience.

\section{Prior Studies}

Studies of an auditor's judgment strategies rely on a cognitive view of expertise, which place emphasis on the investigation of an auditor's knowledge and how it is used. The results from these studies, however, do not show on a consistent basis that experience always leads to better judgments. The schema and cognitive structure concepts proposed in the studies of Gibbins (1984), Waller and Felix (1984), and Kida (1984a) serve as frameworks that help us understand the behavior of auditors in decision making environments. A review of the studies on the relationship of experience and judgment in internal control systems also produced mixed results. Some studies showed a positive relationship between experience and judgment Abodolmohammadi \& Wright, 1987; (Ashton \& Brown; Ashton \& Kramer, both as cited in Charitable, 1996). Libby (1985) investigated whether auditors are more likely to generate frequent errors as possible explanations of unusual fluctuations that occur in financial statements. Libby's results suggest that perceived frequency of the error was a major factor in the auditor's ability to access error hypothesis while conducting analytical review. In addition, Libby also suggested that the frequency of such errors were closely tied to the frequency with which the individual error hypotheses were generated. Still others have found a negative relationship between experience and judgment quality (Hamilton \& Wright, 1982; Trotman \& Wood, 1991). Studies that indicate an increase in knowledge content domain with experience do show consistency when compared with studies in other areas (Choo \& Trotman, 1991; Frederick, 1991; Libby \& Frederick, 1990; Chi et al.,1982). It is therefore reasonable to infer that auditors have specialties in certain tasks and industries (Ashton, 1991). Research on the effects of experience on the knowledge structures of auditors indicates consistent results 
when compared to other areas of auditing (Christ, 1993; Frederick, 1991; Bedard \& Biggs, 1988).

\section{Formal Training And Professional Performance}

Accounting researchers who investigated the formal training of auditors have focused most of their attention on the appropriate academic training for the accounting profession The educational preparation for public accounting has traditionally focused on a 4-year degree program. More recently, however, much discussion has centered on whether a 5-year baccalaureate education is more appropriate for public accountants. A study conducted by Roy and MacNeil in 1967 on the educational requirements of Certified Public Accountants (CPAs) resulted in a debate that eventually led to the adoption of the Common Body of Knowledge (CBOK) by the American Institute of Certified Public Accountants (AICPA) as its official position on the educational program most appropriate for CPAs (Kaplan \& Welker, 1998). The AICPA is currently requiring its newest members to receive more educational training ( 5 years, 150 semester hours) in the hope that graduates will have greater maturity and be better able to apply professional judgment. AICPA members also believe that the business communication skills of graduates should be improved with more educational training, which should result in less on-the job training.

Neuman (1972) examined the nature of auditing exposure provided to students by collecting descriptive data regarding auditing courses offered by colleges. Neumann reported that of the 67 colleges responding only 49 offered one or two auditing courses. In addition, 20 of the 26 schools that offered two audit courses were offering one each at the baccalaureate and post-baccalaureate level. Neumann also found that auditing courses were more procedurally oriented as opposed to conceptual. He also reported that formal writing was becoming an increasingly important requirement in auditing courses. Neuman's study revealed that colleges were engaged in offering instruction in techniques that should have been the responsibility of accounting firms. Whitham (1974) conducted a study to investigate whether CPA firms perceived differences among graduates from different degree programs. The results indicated that respondents evaluated staff assistants as being weak in the areas of mathematical techniques, computer knowledge, knowledge of business law and economics, and command of written and spoken English. Whithman's study did not evaluate individuals by educational background. Although a statistical test was not applied to the collected data, the study concluded that a 5-year program was not needed, since areas of weaknesses could be remedied after an individual entered public accounting.

Schiff (1980) noted that there was disagreement on appropriate academic training for entrance into the public accounting profession. Schiff reviewed the position taken by the American Assembly of Collegiate Schools of Business (AACSB) as well as other supporters of the traditional 4-year program. According to Schiff, the 5-year program would limit entry to the public accounting profession. Schiff's study revealed that the AACSB found that there was no proof that a greater amount of exposure to accounting courses contributed to success on CPA examinations or in public accounting careers. None of the studies, however, have provided a conclusion on the relationship between formal training and professional performance. Results of studies with the exception of (Whitham 1974; Kaplan, \& Welker 1998) do not provide empirical evidence to support their positions on the fouryear formal training program for auditors.

\section{Theory And Research Hypotheses Formulation} setting.

Three hypotheses were tested to examine the effects of the explanatory variables in an audit decision

Formal training as a component of experience has the potential for influencing an auditors' level of comprehension of the audit process. Since very little is known about how formal training affects the auditor's learning of the various aspects of the audit process, it was difficult to predict the direction of its effect. Gibbins's (1984) model suggested that the audit environment shapes the auditor's knowledge structures.

H1: There is a difference in the quality of auditors' performance in terms of their formal training.

Some studies showed no effects attributable to experience (Ashton; Ashton \& Kramer, both as cited in 
Charitable, 1996); Bonner \& Lewis, 1990; \& Trotman \& Wood, 1991. Other studies, however, revealed experience effects on the auditor's knowledge of the audit process Abdolmammadi and Wright, 1987; Choo and Trotman, 1991; Frederick, 1991; \& Hamilton \& Wright 1982)

H2: There is a difference in the quality of performance based on levels of on-the- job training.

The third independent variable was the source of accounting error. Extending Libby (1985 study accounting data and source were manipulated to influence subjects into believing that a specific source was the cause of the fluctuations in the ratios. In this case it was an unrecorded purchase of approximately four percent of purchases. Industry information for the hypothetical client consisted of financial accounting data. Two prior years' audited financial accounting information was given for the client. The current year's financial ratios were given for both the hypothetical client and the industry. The ratios were manipulated to make the two prior years' audited financial ratios similar, while the client's un-audited current year's financial statement and the industry's financial ratios were different. Participants were informed that the client's current year's un-audited ratios were derived from the client's representation of its year-end balances and summaries of expectations based on past audited results. A variation of Libby (1985) study further attention as focused on the client's financial information as the possible cause of the fluctuations in the ratios. Participants were therefore informed that experts who had been preparing the information for the last 6 years prepared industry averages. It was also difficult to predict the outcome based on Fredrick (1991) who found that retrieval of memory depended not only on experience, but also the way in which an auditor's knowledge structures are organized.

H3: There is a difference in the quality of auditors' performance based on the source of accounting error.

\section{Performance}

The dependent measure used to measure the quality of auditors' performance in evidence collection and evaluation consisted of the average quality scores received by participants based on responses to types of evidence and evaluation procedures. Participants were requested to list as many types of evidence and evaluation strategies to support the change in the client's quick ratio. The quality of participants' responses to the analytical review task was measured by applying a quality rating score to each response. A team of expert auditors developed the responses. The expert auditors rated the quality of responses on a scale with a minimum score of 1 and a maximum score of 10 for each response. Quality was measured after being rated by the experts on the criteria outlined in Appendix B.

\section{Procedure And Materials}

The quasi experiment in this study consisted of data in (Appendix A) modifying Libby (1985). The data were obtained from questionnaires administered to participating auditors within two State audit departments. Participants provided responses to specific information. An analytical review task was used to test the quality of auditors' performance as they validated their assumptions through evidence collection and evaluation. The instrument comprised of a folder with the research instrument, and a debriefing questionnaire. The task stressed the purpose of analytical reviews as it relates to determining the cause of unexpected relationships, forms assumptions, which are validated during an information search. Quality responses were measured on a scale with a minimum score of 1 and a maximum score of 10 for each response based on established criteria. (Appendix B).

\section{RESULTS}

\section{Descriptive Statistics}

A total of 100 individuals participated in the study. They performed an analytical task that required them to collect and evaluate audit evidence, as is customary in the analytical review stage of an audit. Subjects were practicing auditors from two audit departments in the State of New York $(\mathrm{n}=100)$. Subjects in the sample were not randomly selected but were instead selected from a large group of auditors who were available to participate in the study. The sample providing the data was therefore a sample of convenience. The participants performed the 
analytical task as part of their regular training sessions. Participants were requested to select their choice of the source of accounting error causing a change in the current year's quick ratio of a hypothetical client. Subjects had a choice of (a) material error, or (b) year-to-year variation.

From the 100 participants, 96 usable responses were obtained. Responses from four participants were excluded from the analysis because three of the four expert evaluators did not give a raw quality score for those participants. The expert evaluators all agreed that the participants' responses were incomplete and as such could not be rated. Data analyzed for the study are based on the scores for the remaining 96 participants.

The descriptive statistics of the formal training of participants, organized into 5 classes, are summarized in Table 1. Formal training ranged from 6 years to 11 years, with a mean of 8.5 years and a standard deviation of .95 years $(n=96)$. Table 1 shows that the distribution for formal training is positively skewed, indicating that a large number of the participants have 8 or fewer years of formal training. Of the 96 participants, 69 were grouped as having formal training of more than 8.5 years, while 27 were grouped as having less than 8.5 years of formal training.

Table 1

Descriptive Statistics By Formal Training Levels

\begin{tabular}{rll}
\hline Formal Training $(\mathbf{y r s})$ & F & 01 \\
\hline $2.5-6.0$ & 68 \\
$6.5-8.0$ & 26 \\
$8.5-10.0$ & 01 \\
$10.5-12.0$ & 01 \\
\hline
\end{tabular}

Descriptive data for on-the-job training are summarized in Table 2. The data are organized in five classes. On-the-job training ranged from 2.5 years to 22.4 years, with a mean of 7.3 years and standard deviation of 2.8 years $(\mathrm{n}=96)$. The distribution indicated that a majority of the participants had 10.4 or fewer years of on-the-job training. Of the 96 participants, 46 were grouped as more experienced--having more on-the-job training-- while 50 were grouped as having less on-the-job training.

Table 2

Descriptive StatisticsBy On-The Job Training Levels

\begin{tabular}{cc}
\hline On-the-Job Training (yrs) & $\mathbf{F}$ \\
\hline $2.5-6.4$ & 38 \\
$6.5-10.4$ & 47 \\
$10.5-14.4$ & 8 \\
$14.5-18.4$ & 2 \\
$18.5-22.4$ & 1 \\
\hline
\end{tabular}

Participants were classified based on the sample mean of 7.3 years of on-the-job training. Those above the mean were grouped together as more experienced, while those below the mean were grouped as less experienced. The dependent measure average quality score was used to investigate the effects of formal training, on-the-job training, and source of accounting error on the quality of auditors' performance in evidence collection and evaluation. Descriptive statistics for the dependent measure average quality scores are summarized in Table 3.

Table 3

Descriptive Statistics By Dependent Measures

\begin{tabular}{cc}
\hline Mean Quality Scores & Accum. Freq \\
\hline $24.0-29.2$ & 17 \\
$29.3-34.5$ & 57 \\
$34.6-39.8$ & 67 \\
$39.9-45.1$ & 80 \\
$45.2-50.4$ & 96 \\
\hline
\end{tabular}


The data were arranged in 5 classes, and ranged from an average score of 24 to 50.4. Participants' average quality scores indicated a mean of 35.6 and a standard deviation of 7.3. The average quality scores of participants were derived from the raw scores provided to the 4 expert auditors.

The expert evaluators rated the quality of participants' responses to evidence collection and evaluation procedures on a scale of 1 to 10 points. The possible scores were based on the four criteria of quality as presented in Appendix B. Calculating coefficient alpha of the total scores given by each expert auditor tested the reliability of the expert evaluators' ratings. An estimated overall alpha of .97 was achieved. For this study an alpha of .80 was considered acceptable. Although instructions for the task indicated to participants that they could list as many responses as possible, each had a total of six responses to the analytical task. Appendix C contains a list of responses from participants to the evidence collection and evaluation procedures. Average quality scores were derived by totaling the raw scores given to each participant by each expert evaluator for the respective response given from the list in Appendix B, and dividing the total raw scores by four, the total number of expert evaluators. The average quality score for each subject was dependent on the number of responses to evidence collected and evaluated and the quality rating assigned by the panel of expert auditors.

\section{Summary Of Regression Analysis}

Data were analyzed with the use of the SPSSX computerized statistical program.

The regression models were as follows:

$$
\begin{aligned}
& \mathrm{y}=\mathrm{f}\left(\mathrm{x}_{1}, \mathrm{x}_{2}\right), \\
& \mathrm{x} 1=\mathrm{f}(\mathrm{ft}, \text { ojt }), \\
& \mathrm{y}=\mathrm{f}\left(\mathrm{ft}, \text { ojt, } \mathrm{x}_{2}\right),
\end{aligned}
$$

$\mathrm{x}_{1}=$ ON-THE-JOB TRAINING

$\mathrm{X}_{2}=$ SOURCE OF ACCOUNTING ERROR

$\mathrm{FT}=\mathrm{QUANTITY}$ OF FORMAL TRAINING,

OJT $=$ ON-THE-JOB TRAINING (QUANTITY OF WORK EXPERIENCE),

$\mathrm{y}=$ Participants' average total quality scores rated by a panel of four experts evaluators based on four criteria of a quality response.

\section{Tests Of The Independent And Dependent Variables.}

The average quality score for each subject was dependent on the number of responses to evidence collected and evaluated and the quality rating assigned by the panel of expert evaluators. The first two equations were solved simultaneously, while the third equation, a reduced-form equation, was used for estimation to avoid the problem of simultaneity. The problem of simultaneity, again, is the bias that appears in estimation of simultaneous equations; these are also called structural equations. One of the remedies for the inconsistency of estimates associated with simultaneous equations is indirect least squares (ILS), which means running OLS on the reduced-form equation.

Multiple regression as a statistical tool was used to examine the extent to which the two independent variables affect or may be used to predict or estimate the dependent variable, auditors' average quality score (performance), corresponding to the given variables of experience or the choice of accounting error. Multiple regression was the preferred method of analysis because two of the independent variables were continuous; its use was also justified based on the literature. (Daniel \& Terrell, 1989). In employing the multiple regression method, an important assumption was considered. That assumption was the independent error component for the valid application of the linear model trend. Any violation of that assumption in this study would give rise to the characteristic of autocorrelation. The results of data analyzed using multiple regressions were based on the average quality scores of 96 six subjects. Every effort was made to include the results of the 100 participating subjects, however, this was not possible.

Summaries of the results of the regression analysis with the average quality score as the dependent variable are reported in Table 4. As indicated, the overall regression model explains that formal training, on-the-job training, and source of accounting error make a $42.5 \%$ contribution to the dependent variable, the average score that 
indicates the quality of auditors' performance. Although the independent variables are responsible for the computed value of only $42.5 \%\left(\underline{R}^{2}\right)$ effect on the quality of performance, the computed $\underline{F}$ value is greater than the $\underline{F}$ value of 2.68 in the $\mathrm{F}$ distribution table. With a $95 \%$ confidence level, the independent variables have a significant effect on the quality of auditors' performance. (p .000) and indicate a reliable predictive effect on auditors' scores. A substantial influence is corroborated by regression coefficients, which are statistically significant $(\mathrm{p}<.05)$ between the independent variables formal education and source of accounting error. However, there is a lack of substantial relationship between the independent variable, on-the-job training, and the dependent variable as indicated by the regression coefficient, which is not statistically significant $(p>.05)$.

The multiple regression models were applied to the data used to test the three hypotheses developed. The standardized regression coefficients for formal training, on-the-job training, and source of accounting error are summarized in Table 4. The standardized coefficients indicated the relative importance of the variables and reveal that formal training has a statistical significant impact $(\mathrm{p}<.05)$ on the quality of auditors' performance in evidence collection and strategies used in validation of auditor's assumptions.

Table 4

Summary of Regression Analysis for Variables Predicting the Quality of Auditors' Performance

\begin{tabular}{lccccc}
\hline Variable & B & SE B & Beta & t & Probability \\
\hline Constant & -8.907 & 6.216 & & -1.433 & 0.155 \\
Formal Training & 4.137 & 0.656 & .539 & 6.307 & 0.000 \\
On-the-Job & & & & 1.602 & 0.113 \\
Training & 0.348 & 0.217 & .134 & & 0.000 \\
Source of & & & & 3.770 & \\
Accounting & 4.435 & 1.176 & .306 & & \\
Error & & & & & \\
$\mathrm{R}^{2=} 0.425$ & & & &
\end{tabular}

\section{Additional Analysis Of The Data Using The Independent Samples Test}

In addition to regression analysis, other analyses of the data were conducted to examine the differences in participant's performance. The first was the independent samples test. Grouping was based on the sample mean of 8.54. Participants with less than the mean number of years of formal training were classified as less educated participants. Those with above the number of mean years of formal training were grouped as more educated participants. Table 5 provides a summary of the results of the group statistics for formal training. Analysis of the group statistics revealed that of the 96 subjects, 27 were more educated, with formal training $\geq 8.54$ years. Sixtynine of the 96 subjects had formal training of $<8.54$ years.

The results of the t test for equality of means, using participants' average scores as the test variable, are summarized in Table 5. The results indicated that there was a statistically significant difference of the means in the independent samples (sig .000).

Table 5

Summary of Group Statistics By Formal Training

\begin{tabular}{lllll}
\hline Variables & $\underline{\mathbf{N}}$ & $\begin{array}{l}\text { Std Error } \\
\text { Mean }\end{array}$ & Std Dev & Mean \\
\hline Scores & 69 & 32.9855 & 5.3771 & 0.64373 \\
Less Educated & 27 & 42.4074 & 7.2358 & 1.3925
\end{tabular}

Independent Samples $\underline{t}$ test for Equality of Means

\begin{tabular}{llll}
\hline & $\underline{\mathbf{t}}$ & Probability & Mean Diff \\
\hline$(\mathrm{N}=96)$ & 6.976 & 0.000 & 9.4219 \\
\hline
\end{tabular}


Three hypotheses were tested in the current research. The first hypothesis tested the quality of auditors' performance in terms of their formal training.

The null hypothesis stated that the quality of auditors' performance in evidence collection and evaluation in terms of their formal training would be the same.

The decision rule is that if the computed $t$ value exceeds table value, then there is a statistically significant difference between the two groups and the null hypothesis is therefore rejected. When the t-test for equality of mean was applied to the independent samples test, the computed $\underline{\mathrm{t}}$ value was 6.976. This $\underline{\mathrm{t}}$ value is significant at the .05 level, since it is greater than the table value of $t .98$. Therefore, the null hypothesis was rejected.

The second hypothesis tested auditors' performance based on their levels of experience (on-the-job training). The null hypothesis stated that the quality of performance in evidence collection and evaluation among levels of experience (on-the-job training) would be the same.

Because the standardized regression coefficients as shown in Table 4 indicated that on-the-job training was not a statistically significant factor contributing to the quality of an auditor's performance ( $\mathrm{p}<.05)$, separate analysis of the data was conducted to examine the extent of the quality of performance along experience lines. Group statistics for on-the-job training, as summarized in Table 6, were used to derive an independent samples test. Participants were grouped using the sample mean of 7.3 years of on-the-job training. Of the 96 participants, 46 had experience above the mean and were grouped as more experienced auditors; the remaining 50 subjects had experience below the sample mean, and were grouped as less experienced auditors. The results of the independent samples $\underline{t}$ test for equality of means is presented in Table 6.

Table 6

Group Statistics for On-The-Job Training

\begin{tabular}{lcccc}
\hline Variables & $\underline{\mathbf{N}}$ & $\begin{array}{l}\text { Std Error } \\
\text { Mean }\end{array}$ & Std Dev & Mean \\
\hline Scores & & & & \\
Less Experienced & 50 & 36.1900 & 8.0267 & 1.1351 \\
More Experienced & 46 & 36.0326 & 6.4310 & 0.9482 \\
\hline
\end{tabular}

Independent Samples $\underline{t}$ test for Equality of Means

\begin{tabular}{lccc}
\hline & $\underline{\mathbf{t}}$ & Probability & Mean Diff \\
\hline & 0.975 & 0.440 & 1.1574 \\
\hline $\mathrm{N}=96)$ & & &
\end{tabular}

Using the average scores of participants as the test variable, the $t$ test for equality of means for on-the-job training showed that the quality performance of participants was not statistically significant at the .05 level. The computed $\underline{t}$ value of .975 is less than the Table value of $t .98$. The independent samples test produced values that were not statistically significant at .444 for a two-tailed test. Due to the large sig value, the null hypothesis is therefore not rejected at the .05 confidence level.

In addition to group statistics for on-the-job training, additional regression analysis was carried out to further investigate the non-significant effects of on-the-job training. The additional multiple regression was used to analyze the range of on-the-job training only for those participants with $<6.4$ but $>10.5$ years of experience. The analysis was carried out using participants' average scores as the dependent variable for those in the lower and upper ranges of on-the-job training. The purpose of the additional analysis was to determine if experience effects would be more evident among those participants. The results indicated that on-the-job training was still not statistically significant $(\mathrm{p}>.05)$. 
The third hypothesis tested the quality of auditors' performance based on their selected source of accounting error.

The null hypothesis stated that the quality of auditors' performance in evidence collection and evaluation as related to the source of accounting error would be the same. The standardized regression coefficients as shown in Table 4 indicate that the source of accounting error is a statistically significant factor contributing to the quality of an auditor's performance (sig. 000).

However, group analysis of the data was also conducted to examine the extent of the difference of the source of accounting error on the quality of participants' performance within groups. Group statistics as presented in Table 7 were used to derive an independent samples test. Participants were grouped based on their selection of one of two sources, namely, material error, and year-to-year variation. Of the 96 participants, a total of 48 selected material error as the source of the accounting error, and collected and evaluated evidence accordingly. Forty-eight subjects also selected year-to-year variation as the source of financial statement error, and likewise collected and evaluated evidence to ascertain the cause of the quick ratio. Participants were grouped based on their source selection. The results of the independent samples $\underline{t}$ test for equality are presented in Table 7.

Table 7

Group Statistics By Source of Accounting Error

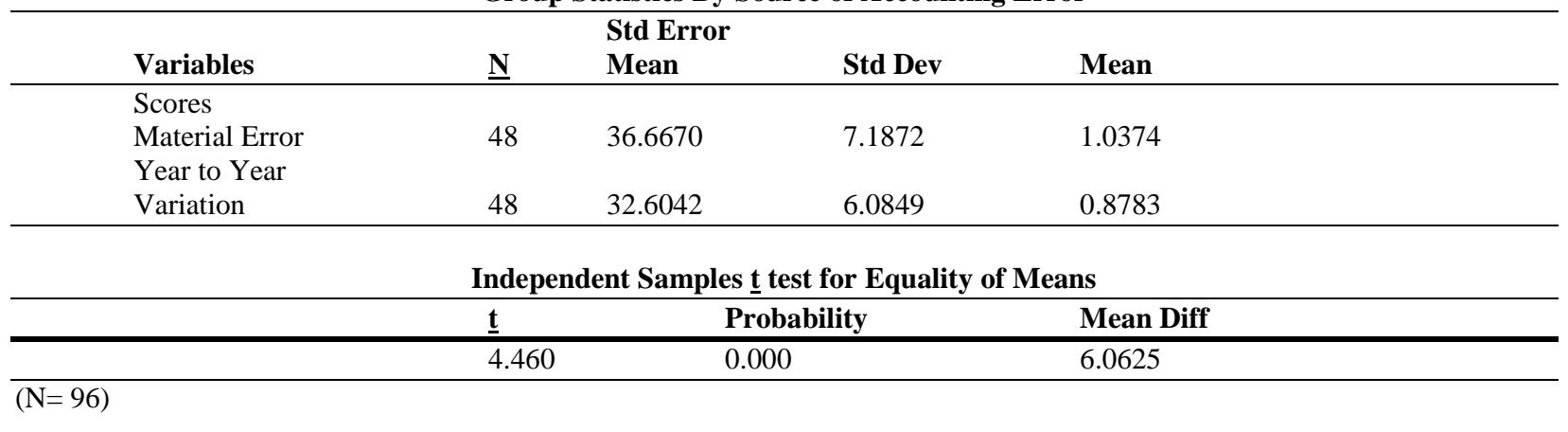

Using the average scores of subjects as the test variable, the $\underline{t}$ test for equality of means for the source of accounting error showed that the quality of participants' performance was statistically significant. The application of the independent samples test produced values that were statistically significant at .000 for a two-tailed test. The computed $\underline{t}$ value of 4.4 is greater than the table value of $\underline{t} 1.98$. Performance between the two groups with respect to the choice of accounting error was significant; therefore, the null hypothesis is rejected.

\section{Discussion}

A number of general conclusions can be made from the results and how these results relate to previous research. The first is that differences in performance between levels of formal training have been identified. Although not identified in prior research, these findings further indicate that individuals who are qualified beyond the 4-year degree will be more qualified and provide more technical competence.

The second conclusion is that auditors do not necessarily perform differently based on their years of on-thejob experience. This finding further indicated that overall, auditors may not exhibit their on-the-job training in all situations that require decision- making. This is consistent with Ashton (1991), who concluded that the investigation of experience effects should involve models that are appropriate in measuring experience conceptualized as task specific. Further conclusions include an indication that auditors may not rely primarily on their past experiences when forming audit judgment, but may instead use basic accounting knowledge in the absence of on-the-job experience. 
The third conclusion is that the findings of this study indicate that formal training has a greater impact on performance than on-the-job training. Although there are no absolute criteria for audit judgments, the auditing profession would have a preference for their more-experienced auditors to perform differently from their inexperienced auditors. Additionally, while much of the analysis in this study focused on the performance of auditors, valuable insights were obtained regarding the training of auditors.

The most important finding was that auditors with more formal training performed differently than their counterparts with less formal education. It is not suggested that the auditing profession should limit their staff to auditors with an advanced degree, but obviously there are a number of factors that enter into that determination. This study provides only a small indication of the perceived benefits of more formal education. Finally, although audit tasks, including the one used in the current study, are designed to identify how effective auditors apply their auditing and accounting knowledge, it is not always easy to identify how much of each is actually used.

\section{APPENDIX A}

\section{Validating Auditor Assumptions Task}

TRC Manufacturing's financial ratios are presented below. The first two columns indicate TRC's financial statement ratios computed from its two prior year's audited financial statements. The ratios in the third column were computed using the current year un-audited financial statements, they are based on summaries and past performances provided by the client. The fourth column contains current year industry averages based on already published audited reports of other industry members. The difference between the three year's ratios could be the result of normal year variation and /or a material error in the un-audited financial statements which has material a effect on net income or, is material in relation to total assets or total liabilities.

\begin{tabular}{lllll}
\hline Ratio & \multicolumn{3}{c}{ FINANCIAL RATIOS } \\
\hline $\begin{array}{l}\text { GROSS MARGIN } \\
\text { Gross Margin } \\
\text { Audited }\end{array}$ & $52.2 \%$ & $\begin{array}{c}\text { 19X1 } \\
\text { Audited }\end{array}$ & $\begin{array}{l}\text { Current Year } \\
\text { Un-audited }\end{array}$ & $\begin{array}{l}\text { Current Year } \\
\text { Industry Averages }\end{array}$ \\
\hline $\begin{array}{l}\text { CURRENT RATIO } \\
\text { Current Assets }\end{array}$ & 4.84 & $52.6 \%$ & 50.8 \\
\begin{tabular}{l} 
Current Liabilities \\
\hline QUICK RATIO
\end{tabular} & 4.86 & 5.44 & 5.70 \\
\hline $\begin{array}{l}\text { Quick Assets } \\
\text { Current Liabilities }\end{array}$ & 2.08 & 2.08 & 2.50 & 2.12 \\
\hline So Adaped & & & \\
\hline
\end{tabular}

Source: Adapted Libby, R. (1985, Autumn). Availability and generation of hypotheses in analytical review. Journal of Accounting Research.

\section{$\underline{\text { Task Instructions }}$}

The error in the financial ratios may be attributed to an accounting error caused by one or more than one mistakes in one of two areas (1) material error, or (2) year-to year-variation. To validate your assumptions you are asked to list both the types of evidence you will use, and evaluation strategies that would allow you to obtain validation. Your approach should be what you would use in a regular audit environment.

You may list as many as 10 types of sources to be used in gathering evidence to validate your assumptions.

(1) List the types of evidence you will collect to investigate the change in the quick ratio. 
(2) List the evaluation procedures you will use to validate your assumptions regarding the change in the quick ratio.

(1) Evidence

(2) Validation Procedures

Example

1.

1.

\section{APPENDIX B}

$\underline{\text { Instructions }}$

To Team of Expert Auditor/Evaluators:

To ensure that responses are objectively evaluated, a minimum score of one and a maximum score of ten was given for each response based on the following considerations of quality. The final score the "average quality score" was developed based on the scores given to each subject.

Measures of Quality

Quality will be measured after being rated on the following considerations:

(a) Level of appropriateness and correctness of the evidence and evaluation strategies,

(b) Level of the subject's' application of knowledge of the underlying accounting process,

(c) Level of the subject's application of knowledge of the relationship between asset and liability accounts,

(d) Level of the subject's understanding of the impact of related accounts used in calculating the quick ratio.

\section{APPENDIX C}

\section{$\underline{\text { Partial List of Types of Evidence Collected }}$}

1. Cash Receipts Journal

2. Short-term Investment Accounts

3. Cash Disbursement Journal

4. Other Asset Accounts

5. Long Term Liability Accounts

6. Accounts Receivable Journal

7. Accounts Payable / Notes Payable Journal

8. Purchases Journal

\section{Validation Procedures for Evidence Collected}

\section{Cash Receipts Journal}

- $\quad$ Investigate for overstated increase in cash.

- $\quad$ Check for overstatement of cash and marketable securities.

- $\quad$ Reconcile cash deposits with cash balances.

- Investigate for cash reducing receivables and not recorded in cash receipts journal.

- $\quad$ Determine if there was incorrect classification of other assets as cash

- $\quad$ Analyze cash for increase due to recording of prior period transactions.

- Investigate for increase in cash due to cost effective measures implemented by client.

$\underline{\text { Short-term Investment Accounts }}$

- Investigate marketable securities increase for inclusion of non -current transactions.

- $\quad$ Examine for overstated marketable securities account.

- Determine liquidation of asset holdings 
- Investigate improper classification of other assets as marketable securities.

- $\quad$ Examine for increase in marketable securities due to sale of equity offerings.

Cash Disbursement Journal

- $\quad$ Reconcile decrease of debt accounts and cash disbursements.

- Determine dividend distributions for rate increase.

- $\quad$ Check for change in periodic payments to suppliers.

Accounts Receivable Journal

- $\quad$ Investigate for reduction in receivables

- $\quad$ Reconcile receivables with corresponding amounts to cash

Accounts Payable/ Notes Payable Journal

- Determine credit extension policy for current year.

- Investigate for late payments affecting accounts payable turnover rate.

- $\quad$ Analyze current liabilities for reductions.

- Investigate current liabilities for reclassification to non-current liabilities.

- $\quad$ Check for decrease in interest rates on current debt.

- Investigation of outstanding debts for possible repayment of current portion.

- Determine if there was application of incorrect accounting method in current year.

- Investigate for reduction in other current liabilities.

- $\quad$ Check for reduction of accrued expenses.

- $\quad$ Analyze for understatement of current liabilities and notes payable.

- $\quad$ Determine the level of increase in trade payables.

- $\quad$ Determine amount of funds received from new loans

- Investigate for unrecorded new debt

- $\quad$ Determine if there is incorrect classification of liabilities.

- Investigate for a decrease in debt maturity for current year.

- $\quad$ Reconcile notes payable to bank or reduction in debt.

- $\quad$ Analyze reduction of accounts payable.

- Determine if new debts have not been recorded.

- $\quad$ Examine short-term debt agreements.

- Investigate for a reduction of debt due to refinancing.

- Determine if purchases were recorded as current or long-term liability.

- Investigate if inventory purchase were from current debt or long term financing.

Purchases Journal

- Investigate if decrease in purchases has resulted in decrease in accounts payable.

- $\quad$ Examine rate of inventory turnover, or change from current debt to long-term financing.

- $\quad$ Purchases recorded twice

- $\quad$ Purchases not recorded

- $\quad$ Purchase returns incorrectly recorded in the next period

$\underline{\text { Sales Journal }}$

- Sales returns not recorded

- $\quad$ Credit sales for subsequent period recorded in current period

- $\quad$ Sales recorded more than once

- $\quad$ Sales returns not recorded

- $\quad$ Sales returns recorded in the next period 


\section{REFERENCES}

1. Abdolmohammadi, M., \& Wright, A. (1987, January). An examination of the effects of experience and task complexity on audit judgments. The Accounting Review, 62, 1-13.

2. American Institute of Certified Public Accountants (1999c). Statement on auditing standards no. 31: Evidential matter. New York: AICPA

3. American Institute of Certified Public Accountants (1999d). Statement on auditing standards No. 56: Analytical procedures. New York: AICPA.

4. Ashton R. (1991, April). Experience and error frequency knowledge as potential determinants of auditor expertise. The Accounting Review, 66, 218-39

5. Bedard, J. C., \& Biggs, S. F. (1991, July). Pattern recognition, hypothesis generation, and other performance in an analytical task. The Accounting Review, 66, 622-42

6. Charitable, R. (1996). The effect of source credibility on independent auditor's judgments. Unpublished doctoral dissertation, Walden University.

7. Choo, F., \&, Trotman, K. (1991, July).The relationship between knowledge structure and judgments for Experienced and Inexperienced Auditors. The Accounting Review, 464-485.

8. Christ, M. Y. (1993, April). Evidence on the nature of audit planning problem representations: An examination of auditor free recalls. The Accounting Review, 68, 304-322.

9. Frederick, D. M. (1991, April). Auditor's representation and retrieval of internal control knowledge. The Accounting Review, 66, 240-258.

10. Gibbins, M.. (1984). Propositions about the psychology of professional judgment in public accounting. Journal of Accounting Research, 22, 103-125.

11. Groveman, H. (1996, October). How auditors can detect financial statement misstatement. Journal of Accountancy, 12-14

12. Hamilton, R. E., \& Wright, W. F. (1982, Autumn). Internal control judgments and effects of experience: Replications and extensions. Journal of Accounting Research, 756-765.

13. Kaplan, A., \& Welker, I. (1998, Fall). Education. Pennsylvania CPA Journal. 69, 17-19

14. Kida, T. (1984a). The effect of causality and specificity on data use. Journal of Accounting Research, 145152.

15. Libby, R. (1985, Autumn). Availability and generation of hypotheses in analytical review. Journal of Accounting Research, 648-667.

16. Libby, R., \& Frederick, D. M. (1990, Autumn). Experience and the ability to explain audit findings. Journal of Accounting Research, 28, 348-367.

17. Neumann, F. L. (1972). Auditing education - a decade of transition: And now? Journal of Accountancy, 133, 87-90.

18. Taylor, D. H., \& Glezen, G. W. (1989). Auditing: Integrated concepts and procedures. New York: John Wiley \& Sons.

19. Trotman, K. T., \& Wood, R. (1991, Spring). A meta-analysis of studies on internal control judgments. Journal of Accounting Research, 29, 180-192.

20. Waller, W.S., \& Felix, W.I. (1984). The auditor and learning from experience: Some conjectures, Accounting Organizations and Society, 9, 383-406.

21. Whitham, R. D. (1974, September). Five years of university education not required. Journal of Accountancy, 93-96.

22. Williams, D. Z. (1978). Accounting education: A statistical survey. New York. 